\title{
POTENSI AMILUM PREGELATINASI DARI BIJI NANGKA SEBAGAI DISINTEGRATOR DALAM PEMBUATAN TABLET PARACETAMOL METODE KEMPA LANGSUNG
}

\author{
Yunilda Rosa ${ }^{1}$, Masnir Alwi ${ }^{2}$, Prizki Ramadoni ${ }^{3}$ \\ 1,2,3 Program Studi S1 Farmasi STIK Siti Khadijah Palembang \\ Email: yunildarosa2018@gmail.com \\ Email : prizkiramadoni1@gmail.com
}

\begin{abstract}
ABSTRAK
Biji nangka mengandung amilum yang dapat digunakan sebagai disintegrator tablet, namun amilum memiliki karakteristik yang kurang baik. Dalam penelitian ini dilakukan modifikasi amilum biji nangka dengan metode pregelatinasi untuk memperbaiki kekurangan amilum. Evaluasi amilum biji nangka dan amilum pregelatinasi meliputi ukuran partikel, sudut istirahat, laju alir, berat jenis, kompresibilitas, rasio hausner dan LOD. Pembuatan tablet menggunakan zat aktif parasetamol dengan metode kempa langsung. Evaluasi massa cetak meliputi sudut istirahat, laju alir, kompresibilitas, rasio hausner dan evaluasi fisik tablet meliputi organoleptis, keseragaman bobot, keseragaman ukuran, kekerasan, kerapuhan, waktu hancur. Hasil penelitian menunjukkan bahwa amilum pregelatinasi memiliki ukuran partikel $150 \mu \mathrm{m}$ sebanyak $92,87 \%$, sudut istirahat $26,1^{0}$, laju alir 7,72gr/det, berat jenis amilum pregelatinasi lebih baik dibandingkan amilum biji nangka, kompresibilitas $1,75 \%$, rasio hausner 1,02, dan LOD sebesar 7,4\%. Hasil evaluasi massa cetak amilum pregelatinasi dengan konsentrasi $10 \%$ lebih baik dibandingkan amilum biji nangka dan secara fisik tablet parasetamol menggunakan disintegrator amilum pregelatinasi $10 \%$ memiliki bentuk, bau, warna dan rasa sesuai persyaratan, keseragaman bobot $1,52 \%$ dengan ukuran diameter tablet yang tidak lebih besar dari tebalnya, kekerasan tablet $6,39 \mathrm{~kg}$, kerapuhan tablet sebesar $0 \%$ dan waktu hancur tablet selama 3,1 menit. Dengan demikian pregelatinasi amilum biji nangka dengan konsentrasi $10 \%$ berpotensi sebagai disintegrator pada sediaan tablet.
\end{abstract}

Kata kunci: biji nangka, amilum, pregelatinasi, parasetamol

\begin{abstract}
Jackfruit seed containing starch which can be used as a tablet disintegrator, but starch has poor characteristics. In this research, a modification of jackfruit seed starch was carried out with a pregelatinized method to correct starch characteristics. Evaluation of jackfruit seed starch and pregelatinized starch include particle size, angle of repose, flow rate, bulk density, compressibility, hausner ratio and LOD. Preparation of tablets using the active ingredient paracetamol by direct compressing method. Evaluation of tablet mass includes angle of repose, flow rate, compressibility, hausner ratio and physical evaluation of tablets including organoleptic, weight variation, size variation, hardness, friability, disintegration time. The results showed that pregelatinized starch had a particle size of $150 \mu \mathrm{m}$ as much as $92.87 \%$, rest angle 26.10 , flow rate $7.72 \mathrm{gr} / \mathrm{sec}$, bulk density of pregelatinized starch was better than jackfruit seed starch, compressibility $1.75 \%$, hausner ratio 1.02 , and LOD is $7.4 \%$. The pregelatinized starch evaluation show mass of tablet with a concentration $10 \%$ are better than jackfruit seed starch and physically the paracetamol tablets using 10\% pregelatinized starch for disintegrator having the shape, odor, color and taste according to standard, weight variation is $1.52 \%$ with diameter size is no more than thickness, hardness is $6.39 \mathrm{~kg}$, friability is $0 \%$ and disintegration time is 3.1 minutes. So pregelatinized jackfruit seeds starch $10 \%$ has the potential to be a disintegrator in tablet formulation.
\end{abstract}

Key word: jackfruit seed, starch, pregelatinized, paracetamol 


\section{Pendahuluan}

Indonesia memiliki banyak sekali sumber kekayaan alam yang pengolahannya belum di gali dan dimaksimalkan, apalagi menjadi produk yang berguna dalam bidang industri farmasi seperti amilum (Haeria, et al. 2018). Amilum dapat ditemukan pada umbi-umbian dan biji, salah satunya pada biji nangka (Kusriani, et al. 2014).

Menurut data dari Badan Pusat Statistik (BPS) Indonesia tahun 2015, di Provinsi Sumatera Selatan jumlah produksi nangka mengalami penurunan pada triwulan ke II (2.987 ton) dan pada triwulan ke III (1.782 ton) di bandingkan jumlah produksi pada triwulan I (3.830 ton), tetapi jumlah produksi buah nangka kembali meningkat pada triwulan ke IV (3.765 ton). Jadi, berdasarkan data tersebut jumlah produksi nangka di Provinsi Sumatera Selatan mencapai 12.364 ton per tahunnya, yang tersebar di berbagai daerah di Provinsi Sumatera Selatan, diantaranya Banyuasin, Empat Lawang, Lahat, Muara Enim, Musi Banyuasin, Musi Rawas, Musi Rawas Utara, Ogan Ilir, Ogan Komering Ilir, Ogan Komering Ulu, Ogan Komering Ulu Selatan, Penukal Abab Lematang Ilir, Ogan Komering Ulu Timur, Lubuklinggau, Pagar Alam, Palembang, dan Prabumulih.

Masyarakat umumnya hanya mengambil bagian daging dari buah nangka untuk di konsumsi, sedangkan biji dari buah nangka selama ini dimanfaatkan terbatas oleh masyarakat hanya dengan cara direbus, disangrai, digoreng, dan dikukus. Lain dari itu biji nangka hanya akan di buang dan menjadi limbah di lingkungan (Kusumawati, et al. 2012).

Menurut penelitian yang dilakukan oleh Kusriani, et al. (2014), biji nangka mengandung amilum, hal ini dibuktikan dengan adanya randemen yang dihasilkan dari biji nangka sebanyak $16 \%$, yang mana randemen yang dihasilkan oleh biji nangka lebih banyak dibandingkan randemen dari biji durian (10\%) dan biji alpukat (4\%). Amilum yang digunakan dalam bidang farmasi berfungsi sebagai bahan tambahan dalam pembuatan tablet memiliki pemakaian yang sangat luas, karena bersifat inert (tidak bereaksi secara kimiawi) dan dapat dicampur dengan hampir semua obat tanpa menimbulkan terjadinya reaksi kimia. Kekurangan amilum adalah sifat alir dan kompresibilitasnya yang kurang baik (Rahayuningsih, et al. 2010).

Apabila ditinjau dari proses pembuatan, terdapat dua jenis amilum yang sering digunakan dalam industri farmasi yaitu amilum alami dan amilum modifikasi. Amilum alami sudah sejak lama digunakan sebagai eksipien dalam pembuatan tablet dengan fungsi sebagai pengisi, penghancur, atau bahan pengikat (Rowe, et al. 2009), meskipun demikin ada keterbatasan penggunaannya, karena tidak dapat dicetak dan laju alir kurang baik (The Departement of Health, 2009). Dan menurut Kelana et al. (2018), pemanfaatan amilum sebagai bahan tambahan dalam pembuatan sediaan tablet masih memberikan hasil kerapuhan dan kekerasan yang buruk, sedangkan persyaratan suatu sediaan tablet harus memiliki tingkat kerapuhan dan kekerasan yang baik. Oleh karena itu amilum alami banyak dipakai dalam formula tablet granulasi basah.

Pembuatan tablet dengan metode granulasi basah memerlukan waktu yang cukup lama sehingga untuk membuat tablet sebaiknya memilih metode kempa langsung untuk menjamin stabilitas obat. Metode kempa langsung dinilai sangat memuaskan karena kebutuhan akan kerja rendah sehingga lebih ekonomis serta bahan obat yang peka lembab dan panas, yang stabilitasnya terganggu 
akibat operasi granulasi dapat dibuat menjadi tablet dengan metode kempa langsung (Voight, 1995).

Oleh karena itu agar amilum dapat diolah menjadi bahan tambahan dalam formulasi tablet metode kempa langsung, maka dilakukan modifikasi amilum menjadi bentuk pregelatinasi. Pada umumnya modifikasi amilum menjadi amilum pregelatinasi dilakukan dengan cara pemanasan suspensi amilum dalam air (Rowe, et al. 2009).

Amilum pregelatinasi memiliki ukuran partikel yang lebih besar yaitu granul. Massa granul ini akan memberikan sifat alir yang lebih baik dan cocok untuk dikempa langsung. Kelebihan dari penggunaan amilum pregelatinasi di banding dengan menggunakan amilum alami adalah membuat sifat fisik tablet menjadi lebih baik, seperti waktu alir granul lebih cepat, kekerasan tablet lebih besar, kerapuhan tablet lebih kecil dan waktu hancur yang lebih lama (Rahayuningsih, et al. 2010).

Menurut penelitian Yusuf et al. (2008) yang melakukan modifikasi amilum singkong secara pregelatin dengan metode cetak langsung membuktikan bahwa modifikasi amilum secara pregelatin mampu memperbaiki sifat alir amilum alami dan kompaktibilitas tablet. Amilum yang dihasilkan memiliki kecepatan alir yang baik yaitu $14,63 \mathrm{~g}$ /detik. Hal ini sesuai dengan Siregar (2008), kecepatan alir yang baik adalah lebih besar dari $10 \mathrm{~g} /$ detik. Sudut diam yang dihasilkan yaitu antara 250 sampai 400, berarti memiliki sifat alir yang baik. Dari hasil pemeriksaan kompaktibilitas diperoleh hasil sebesar $11,49 \%$, bila dihubungkan dengan sifat alir maka amilum singkong pregelatin ini memiliki sifat alir yang sangat baik.

Berdasarkan penelitian oleh Kelana, et al. (2018), amilum pregelatinasi dapat digunakan sebagai bahan tambahan dalam pembuatan tablet kempa langsung. Begitu juga dengan Ningsi, et al. (2016), hasil penelitian mereka menyatakan bahwa amilum pregelatinasi dapat digunakan sebagai eksipien tablet kempa langsung sebagai disintegrator. Sebelumnya juga sudah ada beberapa penelitian yang melakukan modifikasi amilum alami menjadi bentuk pregelatinasi, seperti amilum biji alpukat (Ningsi, et al, 2016), amilum umbi talas (Kelana, et al. 2018), amilum singkong (Rahayuningsih, 2010), dan amilum sagu (Bestari, et al. 2016).

Banyak limbah dari biji buah nangka yang seharusnya bisa dimanfaatkan tetapi hanya di buang tanpa dikelola. Melihat hal inilah, penulis tertarik melakukan penelitian dengan judul Potensi Amilum Pregelatinasi Dari Biji Nangka Sebagai Disintegrator Dalam Pembuatan Tablet Paracetamol Metode Kempa Langsung.

\section{METODE PENELITIAN}

\section{Alat}

Alat yang digunakan adalah mixer, disintegrator taster, friability taster, hardness taster, jangka sorong, mesin cetak tablet, neraca, dan ayakan.

\section{Bahan}

Bahan yang digunakan meliputi biji buah nangka, aquadest, paractamol serbuk, avicel ${ }^{\circledR} \mathrm{PH} 102$ dan talk

\section{Ekstraksi Amilum Alami}

Biji buah nangka dicuci dan dibersihkan dari kulit luarnya, dipotong kecil-kecil di blender sampai halus. Didekantasi dengan aquadest dengan perbandingan 1:12 (1 gr biji nangka ditambahkan $12 \mathrm{ml}$ aquadest) selama 24 jam. Pisahkan endapan amilum yang terbentuk, lalu dilakukan pencucian dengan penambahan aquadest kembali 
secukupnya. Endapan yang diperoleh dikeringkan dalam oven suhu $60^{\circ} \mathrm{C}$ selama 24 jam (Ningsi, et al. 2016).

\section{Pembuatan Amilum Pregelatinasi}

Larutan amilum dibuat dengan konsentrasi $42 \%$ berdasarkan berat kering dengan aquadest dan dipanaskan diatas suhu gelatinisasinya sambil diaduk secara perlahan-lahan hingga diperoleh massa kental, didinginkan dan dikeringkan di oven pada suhu $50^{\circ} \mathrm{C}$ selama 1 x 24 jam. Serpihan yang diperoleh dihaluskan dengan blender (Ningsi, et al. 2016).

\section{Evaluasi Amilum}

Evaluasi terhadap amilum alami dan amilum pregelatinasi meliputi ukuran partikel, sudut istirahat, uji laju alir, uji bobot jenis sejati, bobot jenis nyata, bobot jenis mampat, penetapan indeks kompresibilitas, rasio hausner, dan penetapan loss on drying (LOD).

\section{Pembuatan Tablet}

Pembuatan tablet dilakukan dengan metode kempa langsung yaitu setiap formula, ditimbang bahan-bahan untuk pembuatan 100 tablet dengan dosis paracetamol $500 \mathrm{mg} /$ tablet. Dicampur paracetamol dan amilum biji nangka pregelatinasi hingga homogen. Kemudian dimasukkan Avicel ${ }^{\circledR} \mathrm{PH} 102$ dan pencampuran dilanjutkan kembali. Terakhir dimasukkan talk dan dicampur hingga homogen. Campuran siap dicetak dengan mesin pencetak tablet lalu dilakukan evaluasi tablet (Aeni, 2016).

\section{Evaluasi Sifat Fisik Tablet}

Evaluasi sifat fisik tablet dilakukan meliputi keseragaman bobot, keseragaman ukuran, uji kekerasan tablet, uji kerapuhan tablet, dan uji waktu hancur tablet.

HASIL DAN PEMBAHASAN

\begin{tabular}{|c|c|c|c|c|}
\hline \multirow{2}{*}{ No } & \multirow{2}{*}{ Parameter } & \multicolumn{2}{|c|}{ Hasil Amilum } & \multirow{2}{*}{ Persyaratan } \\
\hline & & Alami & Pregelatinasi & \\
\hline 1. & Ukuran Partikel & $\begin{array}{l}20=0,11 \% \\
40=0,28 \% \\
60=0,17 \% \\
80=1,71 \% \\
100=2,63 \% \\
>100=94,1 \%\end{array}$ & $\begin{array}{l}20=0,12 \% \\
40=0,29 \% \\
60=1,53 \% \\
80=4,47 \% \\
100=92,87 \% \\
>100=0,72 \%\end{array}$ & $\begin{array}{c}>90 \% \\
\text { tertinggal di } \\
\text { mesh no } 100, \\
\text { dan }<0,5 \% \\
\text { tertinggal di } \\
\text { mesh no } 40\end{array}$ \\
\hline 2. & Uji sudut istirahat $\left(^{\circ}\right)$ & $\begin{array}{c}\text { Tidak } \\
\text { membentuk } \\
\text { sudut istirahat }\end{array}$ & $26,1^{\circ}$ & $\leq 40^{\circ}$ \\
\hline 3. & Uji laju alir (g/det) & $\begin{array}{c}\text { Tidak mampu } \\
\text { mengalir }\end{array}$ & 7,72 & $4-10$ \\
\hline 4. & BJ Sejati $(\mathrm{g} / \mathrm{ml})$ & 1,1 & 1,43 & $\geq 1 \mathrm{~g} / \mathrm{ml}$ \\
\hline 5. & BJ Nyata $(\mathrm{g} / \mathrm{ml})$ & 0,46 & 0,43 & - \\
\hline 6. & BJ Mampat (g/ml) & 0,6 & 0,44 & $\begin{array}{c}\text { Tidak } \\
\text { menyusut }>2 \\
\mathrm{ml}\end{array}$ \\
\hline 7. & $\begin{array}{l}\text { Indeks } \\
\text { Kompresibilitas(\%) }\end{array}$ & 28,57 & 1,75 & $\leq 20$ \\
\hline 8. & Rasio Hausner & 1,29 & 1,02 & $\leq 1,25$ \\
\hline 9. & LOD $(\%)$ & 15,6 & 7,4 & $\leq 15$ \\
\hline
\end{tabular}


Dari hasil ekstraksi didapatkan bobot amilum biji nangka kering sebanyak 326,97 gram $(12,11 \%)$.

Jumlah randemen amilum yang didapatkan dari ekstraksi biji nangka tidak lebih banyak dari randemen amilum yang didapatkan dalam penelitian Kusriani (2014) tentang "karakterisasi pati biji buah durian, biji buah nangka, dan biji buah alpukat" dimana randemen amilum yang didapatkan sebanyak 16\%. Perbedaan jumlah randemen yang didapatkan ini dikarenakan perbedaan cara dalam melakukan ekstraksi amilum. Kusriani (2014) melakukan ekstraksi amilum dengan menghaluskan biji nangka dengan penambahan air yang tidak disebutkan, dan larutan biji nangka tersebut diperas menggunakan kain flannel diatas saringan ke dalam wadah, kemudian amilum yang dihasilkan dikeringkan menggunakan oven hingga kering lalu diayak.

Selain itu, perbedaan ini juga dapat dipengaruhi oleh faktor lingkungan tempat tumbuhan tumbuh, dimana menyebabkan kadar amilum pada biji buah nangka bervariasi. Jadi, perbedaan jumlah randemen amilum yang diperoleh ini tidak menunjukkan bahwa salah satu memiliki amilum yang lebih baik atau tidak.

Berdasarkan hasil evaluasi yang telah dilakukan pada amilum biji nangka, untuk amilum alami diperoleh ukuran partikel amilum alami biji nangka adalah $<150 \mu \mathrm{m}$, tidak membentuk sudut diam, tidak mampu mengalir melewati corong, bobot jenis sejati amillum biji nangka adalah $1,1 \mathrm{gr} / \mathrm{ml}$, bobot jenis nyata dan bobot jenis mampat amillum biji nangka adalah $0,46 \mathrm{gr} / \mathrm{ml}$ dan $0,6 \mathrm{gr} / \mathrm{ml}$, nilai indeks kompresibilitas dan rasio hausner amillum biji nangka adalah $28,57 \%$ dan 1,29 serta nilai LOD $15,6 \%$. Sedangkan pada amilum pregelatinasi diperoleh ukuran partikel $424-151 \mu \mathrm{m}$, nilai sudut istirahat amilum pregelatinasi adalah $26,1^{\circ}$, laju alir amilum pregelatinasi adalah 7,72gr/det, bobot jenis sejati amilum pregelatinasi adalah $1,43 \mathrm{gr} / \mathrm{ml}$, bobot jenis nyata dan bobot jenis mampat amilum pregelatinasi adalah $0,43 \mathrm{gr} / \mathrm{ml}$ dan $0,44 \mathrm{gr} / \mathrm{ml}$, nilai indeks kompresibilitas dan rasio hausner amilum pregelatinasi adalah $1,75 \%$ dan 1,02, serta LOD 7,4\%.

Adapun persyaratan yang harus dipenuhi pada evaluasi amilum untuk menunjukkan amilum yang baik dan dapat dijadikan eksipien dalam formulasi tablet metode kempa langsung yaitu ukuran partikel tidak boleh kurang dari $149 \mu \mathrm{m}$ dan tidak lebih dari $420 \mu \mathrm{m}$ (Rowe, 2009), sudut istirahat yang baik yaitu $25^{\circ}-40^{\circ}$ (USP $30^{\text {th }}, 2007$ ), laju alir yaitu 4-10 gr/det (mudah mengalir) dan $>10$ (bebas mengalir) (Aulton, 1988), indeks kompresibilitas dan rasio hausner yang baik untuk dikempa yaitu $\leq 20 \%$ dan $\leq 1,25$ (USP $30^{\text {th }}$, 2007), serta persyaratan LOD yang baik yaitu $<15 \%$ (Rowe, 2009).

Pada penelitian yang dilakukan Mariyani (2012) tentang "Pengaruh Konsentrasi Amilum Jagung Pregelatinasi Sebagai Bahan Penghancur Terhadap Sifat Fisik Tablet Vitamin E Untuk Anjing" amilum alami dari biji jagung memiliki ukuran partikel $\leq 150 \mu \mathrm{m}$, tidak mampu mengalir, tidak membentuk sudut diam, nilai kompresibilitas 51,81\%. Sedangkan amilum pregelatinasi jagung memiliki ukuran partikel $\geq 425 \mu \mathrm{m}$, sifat alir $12,84 \mathrm{gr} / \mathrm{det}$, sudut diam $30,41^{\circ}$, nilai kompresibilitas $21,3 \%$.

Berdasarkan hasil evaluasi diatas, menunjukkan bahwa amilum alami biji nangka tidak memenuhi persyaratan sebagai eksipien tablet kempa langsung dimana amilum biji nangka tidak mampu mengalir melewati corong, tidak membentuk sudut diam, memiliki nilai kompresibilitas, rasio hausner dan LOD 
yang tinggi melewati persyaratan eksipien tablet metode kempa langsung. Sedangkan amilum pregelatinasi memenuhi persyaratan, sehingga bisa dikatakan amilum pregelatinasi memiliki fluiditas dan kompresibilitas yang baik.

\begin{tabular}{|c|c|c|c|c|c|c|c|}
\hline \multirow{2}{*}{ No } & \multirow{2}{*}{ Parameter } & \multicolumn{5}{|c|}{ Hasil } & \multirow{2}{*}{ Persyaratan } \\
\hline & & F1 & F2 & F3 & F4 & F5 & \\
\hline \multirow[t]{6}{*}{1.} & Organoleptis & & & & & & \multirow{6}{*}{ - } \\
\hline & a. Bentuk & $\begin{array}{l}\text { Bulat } \\
\text { pipih }\end{array}$ & $\begin{array}{l}\text { Bulat } \\
\text { pipih }\end{array}$ & $\begin{array}{l}\text { Bulat } \\
\text { pipih }\end{array}$ & $\begin{array}{l}\text { Bulat } \\
\text { pipih }\end{array}$ & $\begin{array}{l}\text { Bulat } \\
\text { pipih }\end{array}$ & \\
\hline & b. Warna & Putih & $\begin{array}{l}\text { Putih } \\
\text { Kecoklatan }\end{array}$ & $\begin{array}{c}\text { Putih } \\
\text { Kecoklatan }\end{array}$ & Putih & Orange & \\
\hline & c. Bau & $\begin{array}{c}\text { Tidak } \\
\text { berbau }\end{array}$ & $\begin{array}{c}\text { Tidak } \\
\text { berbau }\end{array}$ & $\begin{array}{c}\text { Tidak } \\
\text { berbau }\end{array}$ & $\begin{array}{l}\text { Tidak } \\
\text { berbau }\end{array}$ & $\begin{array}{r}\text { Tidak } \\
\text { berbau }\end{array}$ & \\
\hline & d. Rasa & Pahit & Pahit & Pahit & Pahit & Pahit & \\
\hline & e. Tekstur & $\begin{array}{l}\text { Agak } \\
\text { kasar }\end{array}$ & $\begin{array}{l}\text { Agak } \\
\text { kasar }\end{array}$ & $\begin{array}{l}\text { Agak } \\
\text { kasar }\end{array}$ & $\begin{array}{l}\text { Agak } \\
\text { kasar }\end{array}$ & Halus & \\
\hline 2. & $\begin{array}{l}\text { Keseragaman } \\
\text { bobot } \%\end{array}$ & 1,52 & 1,52 & 1,52 & 18,52 & 0 & $\begin{array}{c}\text { Tidak boleh } \\
\text { lebih dari } 2 \\
\text { tablet yang } \\
\text { bobot rata- } \\
\text { ratanya lebih } \\
\text { besar dari 5\% } \\
\text { dan tidak satu } \\
\text { tablet pun yang } \\
\text { bobotnya } \\
\text { menyimpang } \\
\text { lebih dari 10\% }\end{array}$ \\
\hline \multirow{3}{*}{3.} & $\begin{array}{l}\text { Keseragaman } \\
\text { ukuran }\end{array}$ & & & & & & \multirow{3}{*}{$\begin{array}{c}\text { Diameter tidak } \\
\text { lebih dari } 3 \\
\text { kali tebal tablet } \\
\text { dan tidak } \\
\text { kurang dari } 1 \\
1 / 3 \text { tebal tablet }\end{array}$} \\
\hline & $\begin{array}{l}\text { a. Diameter } \\
(\mathrm{cm})\end{array}$ & 11,79 & 11,8 & 11,8 & 11,79 & 12,5 & \\
\hline & b. Tebal $(\mathrm{cm})$ & 5 & 5 & 5 & 4,05 & 4,4 & \\
\hline 4. & $\begin{array}{l}\text { Kekerasan } \\
\text { tablet }(\mathrm{kg})\end{array}$ & 4,51 & 6,39 & 4,23 & 8,03 & 6,6 & $4-8$ \\
\hline 5. & $\begin{array}{l}\text { Kerapuhan } \\
\text { tablet }(\%)\end{array}$ & 1,49 & 0 & 1,51 & 0 & 0 & $<1$ \\
\hline 6. & $\begin{array}{l}\text { Waktu } \\
\text { hancur tablet } \\
\text { (menit) }\end{array}$ & 3,27 & 3,1 & 3,04 & 3,58 & 6,07 & $<15$ \\
\hline
\end{tabular}

Dari uji keseragaman bobot pada setiap formula diketahui bobot rata-rata dari tiap formula adalah F1 0,66gr; F2 0,66gr; F3 0,66gr; F4 0,54gr dan F5 0,7gr. Dari bobot rata-rata yang sudah diketahui tersebut didapatkan hasil penyimpangan dari bobot rata-rata pada F1, F2 dan F3 adalah sampai sebesar 1,52\%, F4 sebesar 18,52\%, dan F5 0\%. Syarat ketentuan keseragaman bobot tablet yang baik adalah tidak boleh lebih dari 2 tablet yang bobotnya menyimpang lebih dari 5\% dan tidak boleh satupun tablet yang bobotnya menyimpang lebih dari $10 \%$ dari bobot rata-ratanya.

Hasil keseragaman bobot dipengaruhi oleh faktor sifat alir amilum. Sifat alir yang baik menyebabkan amilum dapat mengisi ruang cetak secara konstan sehingga tablet yang dihasilkan 
memiliki keseragaman bobot yang baik (Lenny, 2012). Pada tabel diketahui formula F4 memiliki sifat alir yang bersifat sukar mengalir, menyebabkan serbuk tablet paracetamol tidak dapat mengisi ruang cetak tablet secara konstan sehingga dihasilkan tablet dengan bobot yang berbeda-beda.

Dari hasil diatas, diketahui bahwa F1, F2, dan F3 memenuhi persyaratan keseragaman bobot karena memiliki nilai penyimpangan bobot tablet paling besar dibawah $5 \%$, yaitu berturut-turut $1,52 \% ; 1,52 \% ; 1,52 \%$; dan $0 \%$. Sedangkan F4 tidak memenuhi persyaratan keseragaman bobot tersebut, karena memiliki nilai penyimpangan keseragaman bobot paling besar yaitu $18,52 \%$ dari ketentuan yang tidak boleh $>10 \%$. Dimana terdapat 2 tablet yang bobotnya menyimpang lebih dari 5\%, dan terdapat 7 tablet yang bobotnya menyimpang lebih dari $10 \%$ dari bobot rata-ratanya.

Hasil evaluasi keseragaman ukuran tablet setiap formula didapatkan rata diameter seluruh formula F1, F2, F3, F4 dan F5 bertutur-turut adalah 11,79mm; $11,8 \mathrm{~mm} ; 11,8 \mathrm{~mm} ; 11,79 \mathrm{~mm}$; dan $12,5 \mathrm{~mm}$. Sedangkan untuk tebal ratarata dari tiap tablet F1, F2, F3, F4 dan F5 bertutur-turut adalah $5 \mathrm{~mm} ; 5 \mathrm{~mm} ; 5 \mathrm{~mm}$; 4,05mm; dan 4,4mm.

Ketentuan keseragaman ukuran tablet yang beik, yaitu diameter tablet tidak lebih dari 3 kali tebal tablet dan tidak kurang dari $1 \frac{1}{3}$ kali tebal tablet (Dirjen POM, 1979). Dari sini kita ketahui untuk tablet yang memiliki ketebalan 4,05mm, berarti diameter tablet tidak boleh lebih dari $3 \mathrm{x}$ tebal tablet yaitu $12,15 \mathrm{~mm}$ dan tidak boleh kurang dari $1 \frac{1}{3} \times$ tebal tablet yaitu 5,4mm, seperti pada tablet F4. Sedangkan untuk tablet yang memiliki ketebalan $5 \mathrm{~mm}$, berarti diameter tablet tidak boleh melebihi $3 \mathrm{x}$ tebal tablet yaitu $15 \mathrm{~mm}$ dan tidak boleh kurang dari $1 \frac{1}{3} \mathrm{x}$ tebal tablet yaitu $6,7 \mathrm{~mm}$ seperti pada tablet F1, F2 dan F3.

Dengan demikian seluruh tablet F1, F2, F3, dan F4 memenuhi persyaratan keseragaman ukuran tablet, karena tidak ada satupun tablet pada masing-masing formula yang memiliki diameter melebihi 3 kali tebal tablet dan tidak boleh kurang dari $1 \frac{1}{3}$ kali tebal tablet (Depkes RI, 1979). Pada F5 sendiri memiliki keseragaman ukuran yang baik, dimana semua tablet memiliki ukuran diameter dan ketebalan tablet seragam.

Kekerasan tablet merupakan parameter untuk menilai ketahanan tablet terhadap goncangan pada saat pembuatan, pengepakan, dan pendistribusiannya kepada konsumen (Lachman, 2008).

Hasil uji kekerasan tablet tiap formula mendapatkan nilai $\mathrm{F} 14,51 \mathrm{~kg}$; F2 6,39kg; F3 4,23kg; F4 8,03kg; F5 $6,6 \mathrm{~kg}$. Perbedaan nilai masing-masing formula pada tablet dapat disebabkan perbedaan sifat alir tiap formulasi menyebabkan tablet memiliki kekerasan yang bervariasi, yang oleh ukuran partikel yang semakin kecil sehingga semakin banyak massa tablet yang masuk ke dalam pencetak tablet sehingga tablet menjadi makin keras. Diketahui pada F4 sendiri yang memiliki nilai kekerasan tablet paling tinggi, hal ini disebabkan oleh karena pada uji serbuk tablet paracetamol F4 sendiri memiliki nilai kompresibilitas yang tinggi melebihi persyaratannya 20\% yaitu $34,29 \%$. Sehingga ketika dikempa menjadi tablet, nilai kompresibilitas yang tinggi akan menghasilkan tablet yang cenderung semakin keras.

Dimana persyaratan untuk kekerasan tablet yang baik adalah $4 \mathrm{~kg}$ 
sampai 8kg (Parrot, 1971). Dari hasil yang didapatkan diatas menunjukkan bahwa formula F1, F2, dan F3 memenuhi syarat kekerasam tablet yang baik yaitu 4-8kg. Sedangkan F4 tidak memenuhi persyaratan tablet yang baik, karena F4 yang mengandung 10\% amilum alami sebagai disintegrator memiliki nilai kekerasan tablet lebih dari $8 \mathrm{~kg}$ yaitu $8,03 \mathrm{~kg}$ yang berarti tablet $\mathrm{F} 4$ termasuk tablet yang terlalu keras.

Setelah dilakukan evaluasi kerapuhan tablet, diketahui nilai kerapuhan tablet $\mathrm{F} 1$ adalah 1,49\%; F2 0\%; F3 1,51\%; F4 0\%; dan F5 $0 \%$. Kerapuhan tablet menunjukkan kekuatan ikatan partikel-partikel pada bagian tepi atau permukaan tablet yang ditandai sebagai masa partikel yang terlepas dari tablet. Nilai kerapuhan yang tinggi dapat terjadi karena ikatan partikel pada bagian tablet kurang kuat, sehingga adanya gesekan pada bagian tersebut menyebabkan partikel lepas dengan mudah (Lachman, 2008).

Persyaratan kerapuhan tablet yang baik yaitu tidak lebih dari 1\% (Lachman, 2008). Untuk F2 dan F4 memenuhi persyaratan kerapuhan tablet yang baik yaitu kurang dari $1 \%$. Sedangkan untuk F1 dan F3 tidak memenuhi persyaratan kerapuhan tablet yang baik karena memiliki nilai kerapuhan yang tinggi melebihi $1 \%$ yaitu $1,49 \%$ dan $1,51 \%$.

Pada F1 memiliki nilai kerapuhan yang tinggi disebabkan karena distribusi amilum pregelatinasi yang tidak merata sehingga terdapat rongga yang kosong pada tablet dan membuat tablet menjadi rapuh. Sedangkan pada F3 disebabkan karena rendahnya konsentrasi bahan pengikat yang digunakan yang menyebabkan ikatan antar partikel menjadi rendah sehingga partikel satu dengan yang lainnya mudah mengalami pelepasan dan tablet menjadi rapuh.
Diamati dari nilai kekerasan tablet tiap formula, diketahui bahwa semakin tinggi nilai kekerasan tablet maka semakin menurun juga nilai kerapuhan tablet.

Pada evaluasi waktu hancur didapatkan hasil tablet $\mathrm{F} 1$ adalah 3,27 menit; F2 3,1 menit; F3 3,04 menit; F4 3,58 menit; dan F5 6,07 menit. Waktu hancur tablet merupakan waktu yang diperlukan untuk hancurnya tablet menjadi partikel-partikel penyusunnya dan melepaskan obatnya. Faktor-faktor yang mempengaruhi antara lain adalah jumlah bahan pengikat, jumlah bahan penghancur serta tekanan pada saat pengempaan (Sheth, 1980).

Persyaratan waktu hancur yang baik untuk tablet tidak bersalut yaitu tidak lebih dari 15 menit (Depkes RI, 2014). Berdasarkan hasil evaluasi yang didapatkan semua tablet F1, F2, F3, dan F4 memenuhi persyaratan waktu hancur tablet yang baik dimana tidak ada formula tablet yang memiliki waktu hancur lebih dari 15 menit.

Berdasarkan data diatas menunjukkan bahwa semakin besar konsentrasi bahan penghancur (amilum biji nangka pregelatinasi) maka waktu hancur tablet semakin cepat. Semakin tinggi konsentrasi pengikat pada tablet maka semakin lambat waktu hancur tablet.

Dengan adanya bahan penghancur yang bercampur secara merata dalam tablet menyebabkan tablet mengembang dan penyusun tablet akan terdesak dan tablet akhirnya hancur (Siregar, 2010).

\section{Kesimpulan}

1. Amilum biji nangka pregelatinasi memenuhi persyaratan sebagai disintegrator dalam pembuatan tablet metode kempa langsung.

2. F2 dipilih sebagai formula dengan konsentrasi paling optimum yaitu 
$10 \%$ amilum pregelatinasi sebagai disintegrator dalam formulasi tablet paracetamol metode kempa langsung.

3. Tablet dengan amilum pregelatinasi $10 \%$ sebagai disintegrator memiliki sifat fisik yang lebih baik dibanding tablet dengan amilum alami $10 \%$ sebagai disintegrator.

\section{SARAN}

Peneliti selanjutnya disarankan untuk melakukan penelitian lanjut dengan melakukan variasi metode untuk mendapatkan informasi dan data yang lebih banyak dan akurat.

\section{DAFTAR PUSTAKA}

Aeni, Qurratul. 2016. Studi Kemampuan Pati Biji Alpukat Pregelatinasi Sebagai Bahan Penghancur Pada Tablet Paracetamol Kempa Langsung (Skripsi). Makassar: UIN Allaudin Makassar.

Aulton, Michael. 1988. Pharmaceutics: The Science Of Dosage Form Design. New York: Churcill Livingstone.

Bestari, A. N., et al. 2016. Pembuatan Amilum Sagu (Metroxylon Sagu, Rottb.) Pregelatin Dan Material Komposit Sebagai Filler-Binder Sediaan Tablet. Jurnal PIT.

Departemen Kesehatan Republik Indonesia. 1979. Farmakope Indonesia Edisi III. Jakarta: Dirjen POM.

Departemen Kesehatan Republik Indonesia. 2014. Farmakope Indonesia Edisi V. Jakarta: Dirjen POM.
Kelana, A. S., et al. 2017. Formulasi Dan Evaluasi Tablet Kaptopril Menggunakan Amilum Umbi Talas Dan HPMC Yang Dimodifikasi Sebagai Pengisi Dan Pengikat Metode Kempa Langsung. Jurnal Ilmu-Ilmu MIPA UII.

Kusriani, R. H., et al. 2014. Karakterisasi Pati Biji Buah Durian, Biji Buah Nangka, Dan Biji Buah Alpukat. Jurnal Farmasi Galenika. Vol 1 (1).

Kusumawati, D. D., et al. 2012. Pengaruh Perlakuan Pendahuluan Dan Suhu Pengeringan Terhadap Sifat Fisik, Kimia, Dan Sensori Tepung Biji Nangka. Jurnal Teknosains Pangan. Vol 1 (1).

Lachman, et al. 2008. Teori Dan Praktek Farmasi Industri Edisi II. Jakarta : Universitas Indonesia, Press.

Lenny K.S., et al. 2012. Pengaruh Rasio Amilum:Air Dan Suhu Pemanasan Terhadap Sifat Fisik Amilum Singkong Preelatinasi Yang Ditujukan Sebagai Eksipien Tablet. Jurnal Farmasi Udayana Vol. 1(1).

Ningsi, S., et al. 2016. Studi Kemampuan Pati Biji Alpukat (Persea Americana Mill) Pregelatinasi Sebagai Bahan Penghancur Pada Tablet Paracetamol Kempa Langsung. JF FIK UINAM Vol.4 (3).

Parrott, E. L. 1971. Pharmaceutical Technology Fundamental Pharmaceutics. 3rd Edition. Mineapolis: Burgess Publishing Company.

Rahayuningsih, D., et al. 2010. Pengaruh Penggunaan Amilum Singkong Pregelatinasi Sebagai Bahan 
Penghancur Terhadap Sifat Fisik Tablet Aspirin. Jurnal Pharmacy. Vol 07 (03).

Rowe, Raymond, et al.2009. Handbook Of Pharmaceutical Excipients Sixth Edition. Great Britain: RPS Publishing.

Siregar, Charles J.P. dan Wikarsa, S. 2010. Teknologi Farmasi Sediaan Tablet Dasar-Dasar Praktis Cetakan II. Jakarta: Penerbit Buku Kedokteran EGC. Jakarta.

Voigt, R. 1995. Buku Pelajaran Teknologi Farmasi. Yogyakarta: Gajah Mada University Press.

Yusuf, H., et al. 2008. Modifikasi Pati Singkong Pregelatin Sebagai Bahan Pembawa Cetak Langsung. J. Penelit. Med. Eksakta Vol. 7 (1). 